\title{
ESTUDO DO RESFRIAMENTO DE CARCAÇAS DE FRANGO COMBINANDO AR FORÇADO E IMERSÃO EM ÁGUA
}

\author{
L. G. G. Rodrigues ${ }^{1}$, E. I. B. Parisotto ${ }^{1}$, B. A. M. Carciofi $^{1}$ e J. B. Laurindo ${ }^{1}$
}

\author{
${ }^{1}$ Universidade Federal de Santa Catarina, Departamento de Engenharia Química e \\ Engenharia de Alimentos - Florianópolis, SC - Brasil, 88040-900. \\ E-mail para contato: joao@enq.ufsc.br
}

\begin{abstract}
RESUMO - O processo de resfriamento de carcaças de frango até temperaturas de $4{ }^{\circ} \mathrm{C}$ é uma exigência de legislações nacionais e internacionais a fim de garantir a segurança alimentar do produto final. $\mathrm{O}$ método de resfriamento de carcaças por imersão em água fria é o mais utilizado industrialmente, entretanto o resfriamento evaporativo vem ganhando popularidade devido aos limites de absorção de água das carcaças durante o processo imerso. Este estudo investigou o tempo de resfriamento e a perda de massa de carcaças de frango submetidas ao resfriamento combinado de ar forçado e imersão em água em diferentes condições de umidade relativa (UR; 30, 60 e $90 \%$ ) e velocidade do ar (duas velocidades) em um mesmo aparato experimental. Os resultados mostram que o aumento da velocidade e da UR do ar promovem, respectivamente, reduções entre 8 e $9 \%$ nos tempos de resfriamento (até $4{ }^{\circ} \mathrm{C}$ ) e reduções entre $8 \mathrm{e}$ $33 \%$ nas perdas de massa (comparação entre UR) de carcaças submetidas ao resfriamento combinado.
\end{abstract}

\section{INTRODUÇÃO}

O Brasil ocupa uma relevante posição no mercado internacional com respeito à produção e exportação de carne de frango. Esta posição está relacionada em grande parte aos avanços na indústria, por exemplo, na tecnologia usada no resfriamento da carne. Durante o processamento industrial, as carcaças de frango evisceradas apresentam redução na temperatura corporal de aproximadamente 40 para $4{ }^{\circ} \mathrm{C}$ (no ponto mais quente, considerado o centro do músculo peitoral). Esta redução é de suma importância para garantir a segurança alimentar e a qualidade do produto final. Os processos de resfriamento mais utilizados na indústria processadora de carne de frango são os métodos de imersão em água, ar forçado e o resfriamento evaporativo. O resfriamento de imersão em água é uma técnica rápida e de custo relativamente baixo largamente usada em indústrias processadoras de frangos da América do Sul e do Norte. Neste processo as carcaças movimentam-se no interior de tanques contendo água fria ou uma mistura de água com gelo. Durante o processo de imersão, as carcaças absorvem água, que entra, principalmente, nos espaços intercelulares criados durante o rigor mortis (Carciofi e Laurindo, 2007; 2010). No Brasil, a absorção de água pelas carcaças é controlada pelas indústrias e pelo Ministério da Agricultura, segundo legislação específica 
(Portaria $\mathrm{n}^{\circ} 210 / 98$ ) que permite o máximo de $8 \%$ de água absorvida durante o resfriamento de carcaças (Carciofi e Laurindo 2007; Brasil, 2014). No entanto, mercados mais exigentes, como a Europa, restringem a técnica de resfriamento por imersão devido à absorção de água pelas carcaças durante o processamento. Dessa forma, o resfriamento por ar forçado está ganhando notoriedade nos EUA, devido à limitada disponibilidade de água, às restrições ambientais relacionadas ao descarte dos resíduos das indústrias processadoras e também devido a mudanças nos limites de absorção de água pelas carcaças naquele país (Huezo et al. 2007). Os métodos de resfriamento de carcaças de frango por ar forçado geralmente utilizam ar frio diretamente sobre os produtos, em túneis de resfriamento até as carcaças atingirem temperaturas de $4,0^{\circ} \mathrm{C}$ (Zhuang et al., 2009). O método de resfriamento evaporativo de carcaças de frango, um processo misto utilizando água e ar frio forçado, foi desenvolvido com a intenção de combinar as vantagens das técnicas de imersão em água e por ar forçado. Neste método, durante um processo de resfriamento de carcaças de frango por ar forçado em câmaras frias, utilizando baixas temperaturas (de $1{ }^{\circ} \mathrm{C}$ a $4^{\circ} \mathrm{C}$ ), as carcaças podem ser rapidamente imersas água fria ou pulverizadas por uma fina camada de água (Mielnik et al., 1999). O resfriamento evaporativo aumenta a taxa de transferência de calor, minimiza a perda de massa e reduz o ressecamento da pele das carcaças de frango na comparação com o processo realizado somente por ar forçado (Barbut, 2002; Jeong et al., 2011a). Estudos anteriores avaliaram os efeitos das técnicas de resfriamento em imersão em água e ar forçado; ar forçado e o resfriamento evaporativo com respeito à qualidade, rendimento de resfriamento e extensão da vida útil da carne de frango processada (Mielnik et al., 1999; Young e Smith, 2004; Savell et al., 2005; Huezo et al., 2007; Carroll e Alvarado, 2008; Jeong et al., 2011a; Jeong et al., 2011b). Neste contexto, o objetivo deste estudo foi investigar o tempo de resfriamento e a perda de massa de carcaças de frango submetidas ao resfriamento combinado de ar forçado e imersão em água em diferentes velocidades e umidades relativas do ar em um mesmo aparato experimental.

\section{MATERIAIS E MÉTODOS}

\subsection{Aparato Experimental}

O aparato experimental utilizado neste trabalho consistiu de uma câmara frigorífica com dimensões de $0,95 \mathrm{~m} \times 1,02 \mathrm{~m}$ x $0,98 \mathrm{~m}$ (profundidade $\times$ largura $\mathrm{x}$ altura) contendo uma unidade condensadora (Danfoss, modelo 136 LCZ, Osasco, Brasil) e um controlador PID (Novus, modelo N1100, Porto Alegre, Brasil) que opera com umidade relativa (UR) e temperatura controladas no seu interior. Um transmissor incorporando os sensores de umidade e temperatura (Novus, RHT-WM, Brasil) foi utilizado para a medição e auxílio no controle da UR e temperatura do ar no interior da câmara fria. As aquisições dos dados de UR e temperatura foram registrados através do software Field Chart (Novus, versão 1.8) com intervalo de leitura de $5 \mathrm{~s}$. As demais temperaturas no interior da câmara foram medidas com termopares tipo $\mathrm{T}$ e seu registro realizado por um sistema de aquisição de dados (Agilent, modelo 34972A, Santa Clara, EUA).

$\mathrm{O}$ ar frio circulante na câmara foi direcionado por um ventilador (Weg, $1000 \mathrm{rpm}$, Jaraguá do Sul, Brasil) com duas velocidades de 4,07 $\mathrm{m} \mathrm{s}^{-1}\left(\mathrm{~V}_{1}\right)$ e $5,66 \mathrm{~m} \mathrm{~s}^{-1}\left(\mathrm{~V}_{2}\right)$ medidas por 
um anemômetro digital (Testo 425, Lenzkirch, Alemanha). O ventilador estava localizado a $30 \mathrm{~cm}$ das amostras de carcaças de frango e do anemômetro, conforme ilustrado na Figura 1.

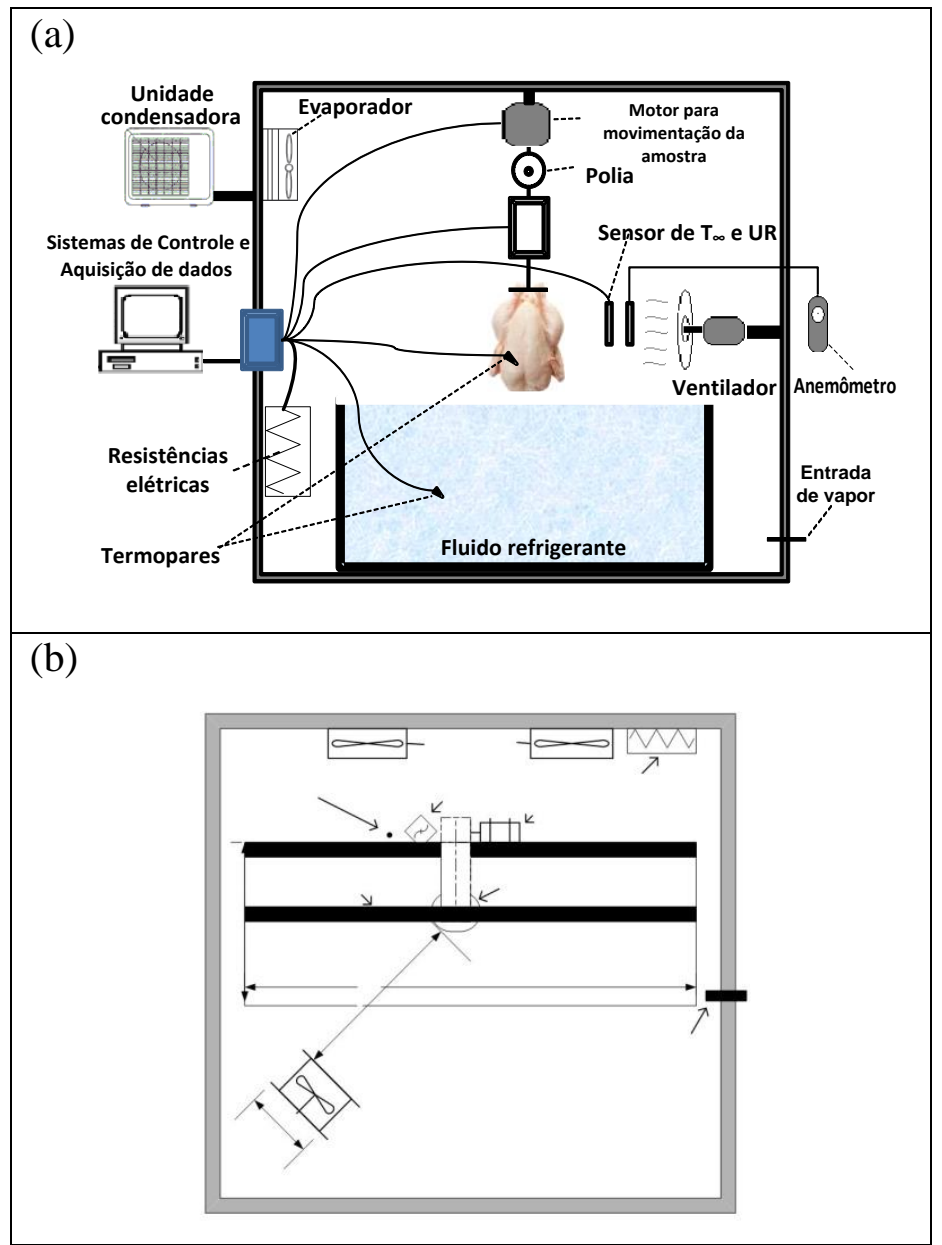

Figura 1 - Aparato experimental especialmente desenvolvido e construído para o estudo do processo de resfriamento deste trabalho. (a) Vista frontal; (b) Vista superior.

Um sistema de movimentação de carcaças de frango, especialmente desenvolvido para este estudo, foi instalado no interior da câmara fria. Um motor automatizado (PPA, New Home - 1/4 HP, Brasil) conectado a cabos de aço e polias que executam o movimento dos cabos na direção vertical, foi utilizado para realizar a imersão de carcaças de frango em uma cuba de aço inox (dimensões internas: $0,98 \mathrm{~m}$ x 0,43 $\mathrm{m}$ x 0,45 m) com $0,139 \mathrm{~m}^{3}$ de água na temperatura de $1{ }^{\circ} \mathrm{C}$. Este dispositivo experimental funciona de maneira automatizada por meio de um controlador lógico programável - CLP (Novus, NSR-CPU18-DR0-AC, Brasil). O sistema de movimentação permite a imersão das carcaças em água fria por um tempo definido e sua remoção para exposição ao ar frio, auxiliando na investigação do processo de resfriamento por um método combinado de imersão em água-ar forçado.

\subsection{Preparo das amostras}

As amostras de carcaças de frango utilizadas no estudo foram oriundas de uma mesma unidade de abate e adquiridas em estabelecimento comercial da cidade de Florianópolis - SC. Anteriormente à realização dos experimentos, as carcaças foram armazenadas em freezer a - 
$18{ }^{\circ} \mathrm{C}$. O armazenamento em freezer foi realizado para garantir a homogeneidade das amostras nesta etapa do trabalho. A massa inicial de cada carcaça variou de 1,8 a 2,5 kg. Para a realização do resfriamento as carcaças foram descongeladas e aquecidas em recipiente com água com temperatura controlada $\left(40{ }^{\circ} \mathrm{C}\right.$ ) até a temperatura do ponto central (a $20 \mathrm{~mm}$ da superfície) do músculo peitoral atingir $38{ }^{\circ} \mathrm{C}$. Em seguida, as carcaças foram mantidas suspensas por $30 \mathrm{~s}$ para drenagem do excesso de água e, posteriormente, foi determinada a massa em balança digital (Filizola, CS - 6, Brasil) com a subsequente inserção dos termopares (tipo T, IOPE, modelo A-TX-TFTF-R-30AWG, São Paulo, Brasil) em profundidades de 20 $\mathrm{mm}$ e $10 \mathrm{~mm}$ a partir da superfície. A primeira posição de $20 \mathrm{~mm}$ levou em consideração a espessura média de um peito de frango com massa média de $2,0 \mathrm{~kg}$, a qual varia entre 40 e 45 $\mathrm{mm}$ de espessura. Em seguida as carcaças foram colocadas na câmara fria com temperatura, UR e velocidade do ar pré-definidos para o resfriamento.

\subsection{Processo de Resfriamento}

As carcaças de frango foram suspensas em um gancho e resfriadas por um processo combinando de ar frio $\left(1,0^{\circ} \mathrm{C}\right)$ e imersão em água fria $\left(1,0^{\circ} \mathrm{C}\right)$ em três UR $(30 \%, 60 \%$ e $90 \%$ ) e duas velocidades do ar $\left(\mathrm{V}_{1} \mathrm{e}_{2}\right)$. As amostras foram imersas em água fria por $5 \mathrm{~s} \mathrm{a}$ cada 15 min de exposição ao ar até a temperatura do centro do músculo peitoral atingir $4{ }^{\circ} \mathrm{C}$, de acordo com a legislação brasileira (BRASIL, 2014). As temperaturas da carcaça, do ar e da água foram monitoradas em intervalos de $5 \mathrm{~s}$ por termopares ligados ao sistema de aquisição de dados (Agilent, modelo 34972A, Santa Clara, EUA).

\subsection{Perda de Massa}

A perda de massa média das carcaças no processo foi obtida a partir da diferença entre as massas antes e após o resfriamento. Os valores são expressos em g de água por $100 \mathrm{~g} \mathrm{da}$ amostra antes do resfriamento.

\subsection{Análise Estatística}

A análise estatítica foi realizada com o auxílio do software Statistica (StatSoft, versão 8.0, 2007, EUA). Os dados foram avaliados pela Análise de Variância (one-way ANOVA) ao nível de propabilidade de $95 \%$. Os resultados foram comparados pelo teste de Tukey. 


\section{RESULTADOS E DISCUSSÃO}

\subsection{Evolução temporal da temperatura do músculo peitoral}

Os dados da evolução temporal da temperatura do músculo peitoral das carcaças de frango submetidas ao processo de resfriamento combinado estão apresentados na Figura 2. Estes dados são referentes à evolução temporal dos sensores de temperatura inseridos nas profundidades de $20 \mathrm{~mm}\left(\mathrm{~T}_{1}\right)$ e $10 \mathrm{~mm}\left(\mathrm{~T}_{2}\right)$ da musculatura peitoral das carcaças.

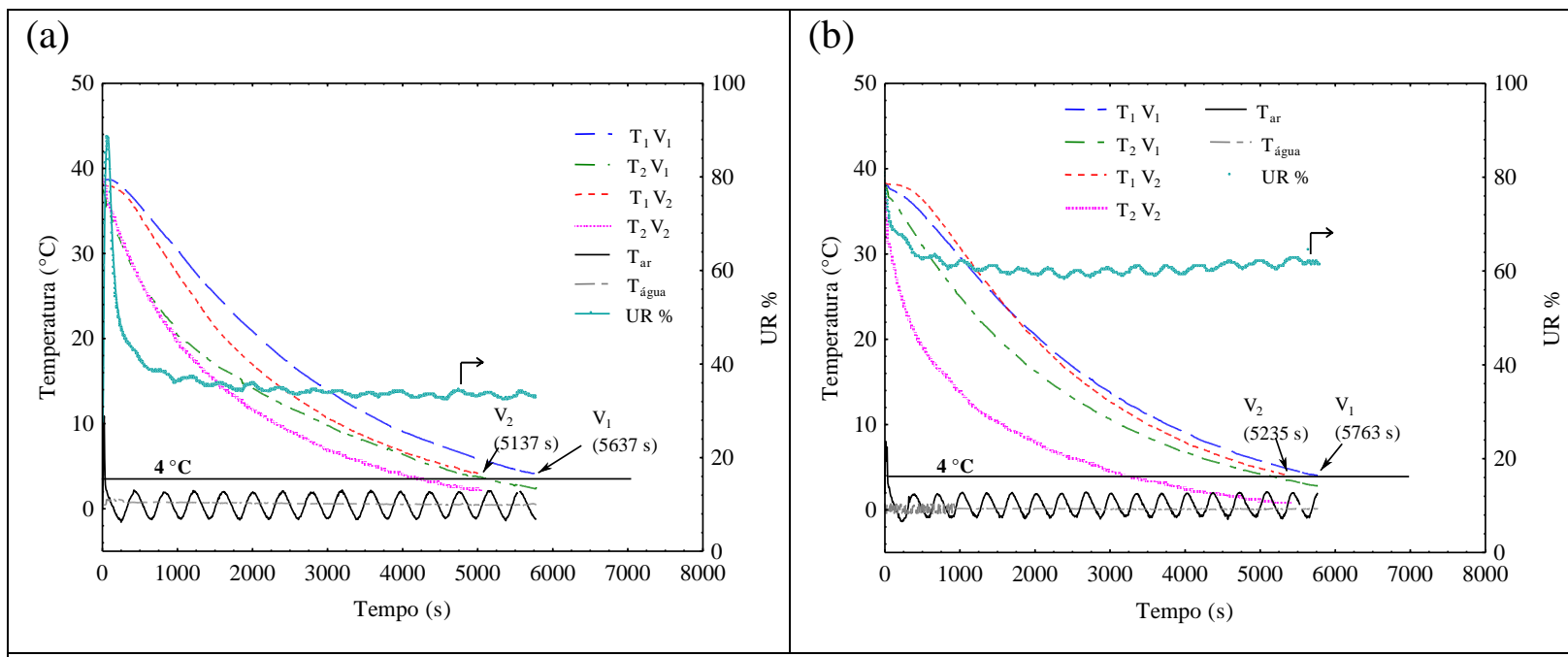

(c)

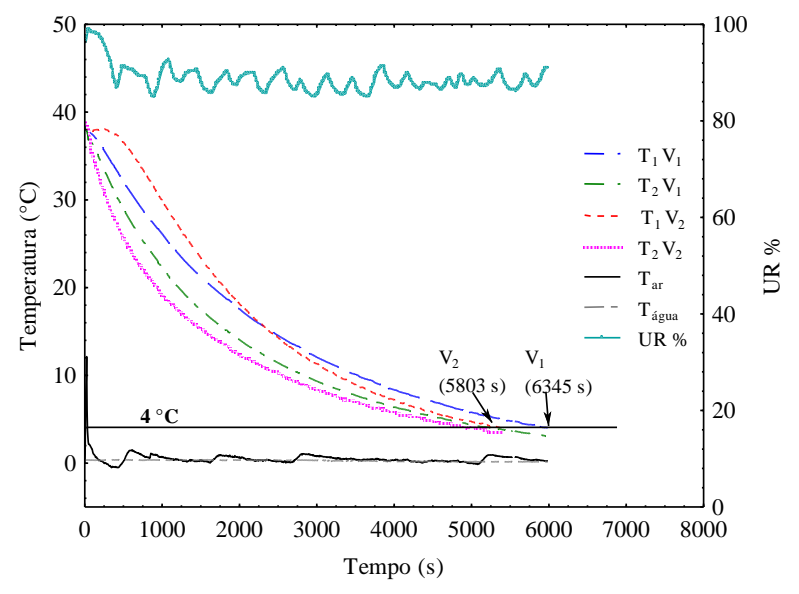

Figura 2 - Evolução temporal comparativa das temperaturas $\mathrm{T}_{1}(20 \mathrm{~mm}$ de profundidade $)$ e $\mathrm{T}_{2}$ (10 $\mathrm{mm}$ de profundidade) inseridas no músculo peitoral das carcaças de frango durante processo de resfriamento combinado em duas velocidades do ar $\left(\mathrm{V}_{1} \mathrm{e} \mathrm{V}_{2}\right)$ : (a) $\mathrm{UR}=30 \%$; (b) $\mathrm{UR}=60 \%$ e (c) UR $=90 \%$.

Conforme esperado, observa-se na Figura 2 uma redução do tempo de resfriamento em aproximadamente $9 \%$, em todas as três condições de UR, com o aumento da velocidade do ar. Nestas figuras verifica-se também a eficiência do controle da UR no interior da câmara 
fria, assim como o controle da temperatura do ar e da água, e a indicação do limite crítico para a temperatura do músculo peitoral $\left(4{ }^{\circ} \mathrm{C}\right)$ durante a realização dos processos de resfriamento. O limite crítico é o valor que o músculo peitoral deve atingir para o processo de resfriamento das carcaças atenderem a todas as exigências legais e comerciais. As reduções temporais de temperaturas do ponto $\mathrm{T}_{2}$ foram mais acentuadas nos instantes iniciais do resfriamento quando do uso da maior velocidade do ar $\left(\mathrm{V}_{2}\right)$ na comparação com a menor velocidade $\left(\mathrm{V}_{1}\right)$. A diferença na taxa de redução das temperaturas da musculatura peitoral das carcaças mostra a forma característica de mecanismo difusivo. O aumento da velocidade da redução das temperaturas do ponto $T_{2}$ é explicado pela redução da resistência difusiva em pontos próximos à superfície da carcaça, promovida pela movimentação do meio de resfriamento, o que também evidencia um mecanismo de transferência de calor convectivo. Este fato foi observado em todas as evoluções temporais de temperatura do resfriamento combinado.

$\mathrm{Na}$ Tabela 1 estão apresentados os resultados experimentais do tempo de resfriamento e perda de massa e seus respectivos coeficientes de variação $(\mathrm{CV}$, razão entre o desvio padrão e a média dos valores) encontrados para o resfriamento de carcaças de frango. Os resultados mostram uma tendência de redução do tempo de resfriamento, de acordo com o aumento da velocidade do ar e redução da UR no interior da câmara fria. Não foram encontradas diferenças significativas nos tempos totais de processo, na comparação entre os experimentos de resfriamento realizados nas UR de 30 e $60 \%$ em ambas as velocidades do ar. Portanto, o uso de uma UR muito baixa (30 \%) não foi eficaz na redução do tempo de resfriamento das amostras.

Tabela 1 - Tempo de resfriamento até $4{ }^{\circ} \mathrm{C}$ e perda de massa com seus respectivos coeficientes de variação $(\mathrm{CV})$. Valores médios \pm desvio padrão

\begin{tabular}{|c|c|c|c|}
\hline $\begin{array}{c}\text { Velocidade do } \\
\qquad \begin{array}{c}\text { ar } \\
\left(\mathrm{m} \mathrm{s}^{-1}\right)\end{array}\end{array}$ & $\begin{array}{c}\text { UR } \\
\%\end{array}$ & $\begin{array}{c}\text { Tempo de resfriamento } \\
(\mathrm{s}) \\
(\mathrm{CV} \%)\end{array}$ & $\begin{array}{c}\text { Perda de massa } \\
\text { (g a cada } 100 \mathrm{~g} \text { iniciais) } \\
(\mathrm{CV} \%)\end{array}$ \\
\hline \multirow{3}{*}{$\mathrm{V}_{1}$} & 30 & $5637 \pm 175^{\mathrm{a}}$ & $1,5 \pm 0,1^{\mathrm{a}}$ \\
\hline & 60 & $\begin{array}{c}5763 \pm 67^{\mathrm{a}} \\
(1,2)\end{array}$ & $\begin{array}{c}1,2 \pm 0,1^{\mathrm{c}} \\
(4,0)\end{array}$ \\
\hline & 90 & $\begin{array}{c}6345 \pm 65^{\mathrm{c}} \\
(1,0)\end{array}$ & $\begin{array}{c}1,1 \pm 0,1^{\mathrm{c}} \\
(6,4)\end{array}$ \\
\hline \multirow{3}{*}{$\mathrm{V}_{2}$} & 30 & $\begin{array}{c}5137 \pm 292^{\mathrm{b}} \\
(5,7)\end{array}$ & $\begin{array}{c}2,1 \pm 0,2^{\mathrm{b}} \\
(7,7)\end{array}$ \\
\hline & 60 & $\begin{array}{c}5235 \pm 216^{\mathrm{b}} \\
(4,1)\end{array}$ & $\begin{array}{l}1,8 \pm 0,2^{\mathrm{d}} \\
(11,4)\end{array}$ \\
\hline & 90 & $\begin{array}{c}5803 \pm 112^{\mathrm{a}} \\
(1,9)\end{array}$ & $\begin{array}{c}1,4 \pm 0,2^{\mathrm{a}, \mathrm{c}} \\
(12,1)\end{array}$ \\
\hline
\end{tabular}

$\mathrm{V}_{1}=4,07 \mathrm{~m} \mathrm{~s}^{-1} ; \mathrm{V}_{2}=5,66 \mathrm{~m} \mathrm{~s}^{-1}$.

${ }^{\mathrm{a}-\mathrm{d}}$ Médias na mesma coluna com letras diferentes indicam diferença significativa $(\mathrm{p}<0,05)$.

Conforme observado na Tabela 1 , na condição experimental de menor velocidade do ar $\left(\mathrm{V}_{1}\right)$ o aumento da UR de 60 para $90 \%$ apresentou a menor redução na perda da massa $(8 \%)$, enquanto que na maior de velocidade do ar $\left(\mathrm{V}_{2}\right)$ o aumento da UR de 30 para $90 \%$ apresentou a maior redução da perda de massa $(33 \%)$ das carcaças. Verifica-se que em uma mesma UR, 
o aumento da velocidade do ar foi significativo $(\mathrm{p}<0,05)$ para perda de massa das carcaças resfriadas nas UR de $60 \%$ e $30 \%$.

Os coeficientes de variação $(\mathrm{CV})$ relativos às variações de massa médias encontradas para os experimentos foram baixos $(\mathrm{CV}<10 \%)$, com exceção de dois casos, indicando que os processos de resfriamento foram reprodutíveis.

\section{CONCLUSÕES}

Os resultados obtidos neste trabalho indicam que o aparato experimental desenvolvido apresenta-se como uma ferramenta útil ao processo de resfriamento de carcaças de frango em diferentes condições experimentais. O método de resfriamento de carcaças de frango combinando o uso de ar frio forçado e rápidas imersões em água fria apresenta-se como uma alternativa ao processo totalmente em imersão em água, que é largamente utilizado em escala industrial. O aumento da velocidade e da UR do ar promovem, respectivamente, reduções entre 8 e $9 \%$ nos tempos de resfriamento (até $4{ }^{\circ} \mathrm{C}$ ) e reduções entre 8 e $33 \%$ nas perdas de massa (comparação entre UR) de carcaças submetidas ao resfriamento combinado. Estas variações da velocidade e da UR do ar mostraram-se apropriadas, indicando que ambas são críticas para descrever as evoluções temporais de temperatura durante resfriamento.

\section{AGRADECIMENTOS}

Os autores agradecem ao CNPq e a CAPES pelo suporte financeiro.

\section{REFERÊNCIAS}

BARBUT. S. Past and future of poultry meat harvesting technologies. World's Poult. Sci. J., vol. 66. P. 399-410. 2010.

BRASIL. Ministério da Agricultura, Pecuária e Abastecimento - Secretaria de Defesa Agropecuária. Regulamento técnico da inspeção tecnológica e sanitária de carnes de aves. Portaria $\mathbf{N}^{\circ}$ 210, Novembro, 1998. Acesso em Janeiro de 2014.

CARCIOFI, B. A. LAURINDO, J. B. Water uptake by poultry carcasses during cooling by water immersion. Chem. Eng. Proc. 46, p. 444-450. 2007.

CARCIOFI, B. A. LAURINDO, J. B. Experimental results and modeling of poultry carcass cooling by water immersion. Ciênc. Tec. Ali. 30 (2), p. 447 - 453. 2010.

CARROLL. C. D. ALVARADO, C. Z. Comparison of Air and Immersion Chilling on Meat Quality and Shelf Life of Marinated Broiler Breast Fillets. Poult. Sci. 87, p 368-372. 2008.

HUEZO, R.; SMITH, D. P.; NORTHCUTT, J. K.; FLETCHER, D. L. Effect of Immersion or Dry Air Chilling on Broiler Carcass Moisture Retention and Breast Fillet Functionality. J. Appl. Poult. Res. 16, p. 438 - 447. 2007. 
JEONG, J. Y., JANARDHANAN, K. K., BOOREN, A. M., HARTE, J. B., KANG, I. Breast meat quality and consumer sensory properties of broiler carcasses chilled by water, air, or evaporative air. Poult. Sci. 90, p. 694 - 700. 2011a.

JEONG, J. Y.; JANARDHANAN, K. K.; BOOREN, A. M.; KARCHER, D. M.; KANG, I. Moisture content, processing yield, and surface color of broiler carcasses chilled by water, air, or evaporative air. Poult. Sci. 90, p. 687 -693. 2011 b.

MIELNIK, M. B.; DAINTY, R. H.; LUNDBY, F.; MIELNIK, J. The effect of evaporative air chilling and storage temperature on quality and shelf life of fresh chicken carcasses. Poult. Sci. 78, p. 1065-1073. 1999.

SAVELL, J. W.; MUELLER, S. L.; BAIRD, B. E. The chilling of carcasses. Meat Sci. 70, p. 449 - 459. 2005.

YOUNG, L. L.; SMITH, D. P. Moisture Retention by Water- and Air-Chilled Chicken Broilers During Processing and Cutup Operations. Poult. Sci. p. 119 - 122. 2004.

ZHUANG, H.; SAVAGE, E. M.; SMITH, D. P.; BERRANG, M. E. Effect of dry-air chilling on sensory descriptive profiles of cooked broiler breast meat deboned four hours after the initiation of chilling. Poult. Sci. p. 1282 - 1291. 2009. 